\title{
Removing the invisibility cloak: Using space design to influence patron behavior and increase service desk usage
}

Stephanie Pierce ${ }^{\mathrm{a}^{*}}$ and Amanda Schilling ${ }^{\mathrm{b}}$

${ }^{a}$ Physics Library, University of Arkansas, Fayetteville, AR, United States; ${ }^{b}$ Bizzell Memorial Library, University of Oklahoma, Norman, OK, United States

365 N. McIlroy Ave, University of Arkansas Libraries, PHYS 221B, Fayetteville, AR 72704, sjpierc@uark.edu 


\section{Removing the invisibility cloak: Using space design to influence patron behavior and increase service desk usage}

In small branch libraries, patrons seeking assistance from library staff outside of the dedicated single-service desk often results in large staffing inefficiencies. This paper presents a case study in which the authors applied behavioral psychology models to a branch library's space arrangement to identify possible factors influencing patron service point choices. A subsequent full space rearrangement was instituted which utilized human behavior research, service desk design principles, and low-cost methods to create a space that reduced barriers and influenced patrons back to the main service desk. The paper reports on the 11-month study that followed and the impact the rearrangement had on patron behavior. Results indicate that simple rearrangement of existing furniture and equipment into new configurations have direct influence on service desk usage and can encourage new patron behaviors. Space and human behavior are inherently connected and library managers should establish goals for how they envision their spaces to be used and arrange them in ways that encourage wanted behaviors.

Keywords: academic library; space design; service desk; reference; circulation; human behavior; floor plans 


\section{Introduction}

Patrons visit libraries for a multitude of reasons and make conscious decisions regarding how they use library spaces, resources, and services. Library space designs can often influence these behaviors subconsciously while simultaneously, positively or negatively, impacting a patron's feelings and perceptions of the library.

The service desk is one major spatial element which can greatly impact a patron's perception. Patrons want and expect a clearly defined focus point where they can seek assistance (Bartle, 1999). The ability to easily identify, access, and interact with staff at the service desk in a positive manner is important for encouraging its use. Low desk interaction statistics may indicate spatial issues, which should be investigated and addressed.

A library's space design should also be reassessed when data indicates patrons are seeking assistance from library staff away from the dedicated service desk. This type of patron behavior suggests the spatial design of the service desk may be causing negative patron perceptions, and the resulting patron behavior can cause staffing inefficiencies. This is especially true in small academic branch libraries where resources are limited and such inefficiencies can result in a large impact on the daily operations and management of the library.

So how do library managers, especially academic branch managers, address service desk and space design issues when financial resources are minimal and full-scale redesign/renovations are out of the question? Can the simple rearrangement of space and furniture really influence patron traffic patterns and choices in small spaces in order to rebalance inefficiencies and perceptions? To address these research questions, an 11-month space study was undertaken at the University of Arkansas' Physics Library branch.

\section{Literature Review}


To understand the research presented in this article, it is important to review the literature from two perspectives: service desk design and human behavior.

\section{Service Desk Design}

Patrons come to academic branch libraries for many reasons, but research shows that patrons expect a clearly defined focus point in the form of a service desk regardless of their reason for visiting (Bartle, 1999). Library and Information Science (LIS) research of the service desk is abundant regarding size, arrangement, and models of service, but regardless of the name or arrangement the need for an easily identifiable place to seek assistance has remained the same for library patrons. Service desk discussions in the literature are often framed within a mediumto-large size library's overall space design. Research has also begun to explore the library as a place through the application of human behavior research in order to examine how design elements influence patron behaviors within their various spaces as well as how perception of access services personnel can affect approachability and use (Aabo \& Audunson, 2012; Baker et al., 2018; Bonnet \& McAlexander, 2012; Bonnet \& McAlexander, 2013; Cha \& Kim, 2015; Cortes-Villalba, Gil-Leiva, \& Artacho-Ramirez, 2017; Houston, 2015; Kim, 2016; Mandel, 2016; Maxymuk, 2010; O'Kelly, Scott-Webber, Garrison, \& Meyer, 2017; Waxman, Clemons, Banning, \& McKelfresh, 2007). Research is lacking, however, an analysis of how library space design impacts small academic branch libraries which have limited space, resources, and staff coupled with the inability for large-scale changes. This paper attempts to fill this gap in the literature by focusing on the intersection of space design and assistance-seeking behavior.

Larason and Robinson (1984) asserted that before patrons can seek assistance they must first be aware access to it exists. The service desk area is often key to establishing this 
awareness. To assist library managers with the designing and planning of their service desk areas, Crooks (1983) established three key framing questions they should ask themselves:

(1) What are the traffic patterns in the area?

(2) What tasks are being performed at the desk?

(3) What are the physical characteristics?

Many researchers have agreed that the physical service desk should be located in a highly visible location; be easily accessible; designed to encourage both short and long interactions; and be flexible in order to address future needs (Becket \& Smith, 1986; Larason \& Robinson, 1984; Bartle, 1999; Crooks, 1983; Pierson, 1985; Humphries, 1993). When planning desk services there hasn't been a more divisive discussion in LIS literature than the debate of whether separate circulation and reference desks should exist or if they should be combined into a single-service point. Barbara Ford (1986) provided one of the earliest arguments for a consolidated approach as she challenged the efficiency and effectiveness of two desks. Many LIS researchers, who viewed Ford as an advocate for the removal of a reference desk in favor of centralized, single-service point, would echo her call (Lewis, 1995; O'Neill \& Guilfoyle, 2015; Campbell, 2007). This research suggested that by moving to new service and staffing models through the use of a single-service desk and the "referral" or "consultation" model of reference, staff resources and expertise are optimized (Sider, 2016; Oud \& Genzinger, 2016; Arndt, 2010; Miles, 2013; Venner \& Keshmiripour, 2016).

Arndt (2010) noted by no longer having a separate desk staffed by librarians to provide walk up reference assistance, libraries were able to increase meaningful reference encounters with librarians, including increasing the number of consultation appointments. Oud and Genzinger (2016) also saw both improved services and quality while emphasizing librarians now 
had more free time to engage in other duties, primarily outreach to faculty. Still, transitioning to a single-service point impacts both staffing requirements and training. Studies on the staffing of single-service points have concluded that most assistance provided could be handled by trained student assistants and paraprofessional staff, allowing librarians to handle more complex reference interactions (Arndt, 2010; Dinkins \& Ryan, 2010; Ryan, 2008; Schulte, 2011). Venner \& Keshmiripour (2016) assessed that by consolidating desks and services while participating in the reference referral model of service, as the Physics Library branch does, allowed management to (1) use staff resources effectively, (2) modernize services, (3) expand cross-training, and (4) develop a more engaged and active learning environment for staff and student assistants.

Much like with the debate of consolidation of services, LIS researchers have long debated what constitutes the "perfect" service desk with the most debated element being desk height versus counter height (Morgan, 1980; Pierson, 1977; Macdonald, 1986). Researchers ultimately concluded a combined approach served patron and staff needs best (Heikkila-Furrey, Kearns, \& Littrell, 2007; Warnement, 2003). While useful to understanding where the literature has focused to date, counter height was not a factor in the Physics Library's space redesign due to the use of a desk height service point throughout the study.

\section{Patron Behavior and Space Design}

Proper space planning can maximize staff and service efficiencies. It can also influence patron behaviors, helping to ensure services and staff are being used by patrons in the intended ways. The discussion of human behavior in relation to library space design and service desk usage in LIS research is limited. Larason and Robinson's (1984) approachability model was one of the first to propose a link between service desk design and patron behavior. This model, which was influenced by human engineer Ernest McCormick's (1970) principles of arrangement, asserted 
that the probability of a patron approaching the service desk for assistance was based on awareness of availability and a patron's calculation of need weighed against the psychological and physical "costs" of approaching the desk. Four key areas impact a patron's likelihood of approach (1) communication and promotion of service, (2) floor plan layout, (3) positioning, and (4) personal space. Follow-up LIS research on a patron's choice to seek assistance based on perceived cost (conscious or subconscious) has been sparse. Van Beynen, Pettijohn, and Carrel (2010) examined this topic through the application of pedestrian choice behavior research at the University of South Florida's Poynter Memorial Library to understand patron movements throughout their library and increase engagement with its offerings, including the service desk.

\section{Human Behavior}

Behavior setting theory and the role of economy of movement in pedestrian choice are two areas of human behavior research that were applied by the researchers in their case study.

Roger Barker introduced the concept of behavior setting theory in his 1968 book, Ecological Psychology, which provided a "multidimensional model of behavior that includes consideration of place, time, social organization, actions and goals" ("Barker, Roger Garlock," 2002). Behavior settings, because they combine both physical and social elements of the environment into one identifiable unit, are considered to be extremely influential on human behavior (Scott, 2005). Behavior setting research has many interdisciplinary applications and is often used to assess how spaces and the objects situated within them are influencing human behavior.

While behavior setting theory explains how environments and their elements can cue behaviors, the economy of movement application to pedestrian choice analyzes the costs and benefits of actions. Researchers of pedestrian choice study the interaction between pedestrian 
behavior and the environment. R.L. Moore (1953) was the first to introduce the economy of movement concept into pedestrian choice research after analyzing groups of people crossing the street and determining the most frequently selected path often required the least amount of effort. However, it was the follow up singular research of Stephen Bitgood (2006) and his joint research with Stephany Dukes (2006) on the economy of movement and its relation to the general value principle and pedestrian choice that is the most applicable to our study. Both studies assert that humans, consciously and subconsciously, evaluate movement choices based on perceived costs and that the perceived benefits must outweigh these costs for an individual to select a certain path and/or destination. Their findings were later reconfirmed during a study to investigate whether group size influenced pedestrian choice (Jazwinski and Walcheski, 2011). As a result, the economy of movement proves to be a "powerful empirical principle in understanding how pedestrians move through their environment" (Bitgood and Dukes, 2006, pg. 402).

The implication, when applied to library space settings, is that as patrons are interacting with library spaces, they are assessing the way libraries have utilized interior design mechanisms to plan their spaces and are calculating the cost of navigating these arrangements when seeking help. Spaces and desks should be designed to encourage positive behavioral outcomes (patrons seeking help) by reducing perceived costs (pathway barriers) in order to increase benefits (ease of access to services, desks, and equipment). Van Beynen, Pettijohn, and Carrel (2010) were the first to apply pedestrian choice and Bitgood's general value principle research (2006) on movement within a LIS space design context. Their research indicated, while paying close attention to natural pathways, (1) that libraries need to determine what resources and services should be located immediate to their entrances to reduce their "costs" and encourage increased 
interactions and (2) libraries should increase "benefits" by redesigning their non-desirable spaces into desirable locations.

The review of literature discussed in this section is key to understanding how a library's physical space design can impact services and influence patron behavior. By recognizing the interconnectedness of space design and human behavior, librarians can affect how their spaces and services are perceived and used in order to encourage intended behaviors and increased efficiencies (van Beynen et al., 2010).

\section{Institutional Context}

Classified as a Carnegie Mellon R1, highest research activity, institution, the University of Arkansas is made up of nine different colleges that serve undergraduate and graduate students, and faculty. The University inhabits a single Fayetteville, AR, campus with a population of over 27,000 students and faculty. The University Libraries consists of David W. Mullins Library, the Fine Arts Library, the Chemistry and Biochemistry Library, Special Collections, the University of Arkansas Law Library, and the Physics Library. The David W. Mullins Library is the main campus library and houses all central library operations as well as Special Collections. As of 2017, the University Libraries' collection consists of over 2 million monographs; 92,000 serials, government documents; and 497,000 audiovisual items which are housed across the various library branches and an off-site high density annex facility. University Libraries employs 35 librarians, 72 staff members, 9 graduate assistants, and a number of student workers.

The Physics Library is a departmental branch library housed within the Physics Building on the south-side of campus. The Physics Library branch consists of 1 faculty librarian, 1 fulltime staff member, 1 part-time staff member, 1 graduate assistant, and multiple student workers. The total square footage of the library is 2,033 sq. ft. which includes the librarian's office (109 
sq. ft.); a quiet room for study and stack holdings (447 sq. ft.); and a main room where computer terminals, collaboration tables, and the majority of print collections are housed (1,477 sq. ft.). The local collection is made up over 11,000 monographs, 1,600 print serials, and course reserve items.

The Physics Library operates Monday through Friday for a total 62 hours a week. Operating hours are reduced during class breaks, intersessions, and summer semesters. For the five-year period 2013 to 2017, the Physics Library saw approximately 63,000 annual visitors making it the second most visited library on campus behind the main branch, Mullins Library. Over this time period the library recorded the majority of foot traffic during the months of April, September, and October and the least in June and July. During the fall and spring semesters of the same five-year period, the average number of visitors per day was 303 . On an average day in the Physics Library, the busiest time occurs between 9am and 6pm when there are between 15 and 30 visitors an hour. Due to its popularity, ensuring services are parallel to Mullins Library is critical. However, while Mullins Library employs separate reference and circulation desks, the Physics Library utilizes a single-service desk staffed by students, the library's graduate assistant, and an evening part-time staff member who handle both reference and circulation transactions. Staff refer complex reference transactions to the librarian and library supervisor when needed, who each have separate desks that are also easily accessible by patrons.

The Physics Library has had to be innovative over the years to balance its collections, services, and space needs without any change to its existing structural layout. At the end of the fall 2016 semester statistics showed that the majority of patron interactions were occurring at the librarian and the library supervisor's desks rather than the main service desk. This unintended traffic flow pattern prevented both the librarian and library supervisor from working on daily 
duties, research, projects, and providing in-depth reference assistance. Instead, they were devoting most of their time to handling circulation and ready-reference/directional transactions for patrons. Because the bulk of patron assistance was falling to the library supervisor and librarian, these employees could not fully devote their time to tasks related to the management and operations of the branch library. The end result was having service desk staff who no longer felt engaged or invested in their role of helping the library function, as the majority of patrons did not interact directly with desk staff.

\section{Turning Theory into Practice}

For this study a combination of Larason and Robinson's (1984) approachability model and Bitgood and Duke's (2006) economy of movement principles was applied along with a physical rearrangement of the space. The goal of modifying patron behavior and encouraging use of a particular service desk location was achieved, with patron interaction data showing that service desk staff are fielding a greater percentage of patron questions post reconfiguration.

The approachability model states that the likelihood a service desk will be approached involves patrons establishing their need and then calculating whether or not it warrants approaching the service desk for assistance (Larason \& Robinson, 1984). These calculations take into account awareness of the desk and services provided, their psychological costs (cost to pride, self, or other mental attributes) and the physical costs (time and effort related to getting to the service point and potentially waiting). To better understand the important role of physical cost within the equation, economy of movement, ways which people minimize time and effort of their behavior, can be applied. Decreasing patrons' costs (least amount of time and effort applied) increases their perceived benefits/experience of their destination (Bitgood, S. \& Dukes, 2006; Bitgood, Stephen, 2006; van Beynen et al., 2010). 
The Physics Library's main space is 1,477 sq. $\mathrm{ft}$. As a result of the small space, awareness and approachability of service desks and staff for assistance was determined not to be impacted by the library's space arrangement. The key issue centered on patrons seeking assistance from staff at the library supervisor desk or librarian desk rather than at the designated main service desk. The service desk was assessed for the study, and it was found that it already followed key suggestions from the approachability model. It was centrally placed in a high visibility, high traffic area in front of the single entry and exit point. Despite this, patrons sought both circulation and reference assistance from the librarian and library supervisor's desks over the service desk 63\% of the time in FY 2016 and 40.4\% in FY 2017 prior to the space rearrangement in August 2017. While proximity to a point is important, it also not enough to attract usage. Costs, packaging (relationship to other points of need), and awareness all play a role in a service desk being used by patrons (Larason \& Robinson, 1984).

Prior to the library's rearrangement all major destinations (computer terminals, printers, copiers, scanners) and course reserves were located in proximity to the library supervisor's and librarian's work spaces. Bitgood and Dukes' (2006) economy of movement and pedestrian choice research suggest that the preference for seeking assistance from these service points over the service desk can be attributed, at least in part, to perceived higher "costs" and lower "benefits" for approaching the service desk.

In an early attempt to recommunicate the purpose of the service desk, course reserve materials were moved from the librarian's office into a cabinet behind the service desk in fall 2016. No other library aspects were altered during this process, and the percentage of circulation transactions occurring at the service desk rose from $37.4 \%$ to $50.6 \%$ following the move. Even small changes, like location moves, can influence and adjust patron behavior. 
Despite the increased usage of the service desk following the course reserves move, patrons were still seeking circulation assistance from the librarian and library supervisor more than a third of the time. To ensure library personnel's time and expertise were being maximally utilized a larger scale rearrangement of the space was needed to encourage patron traffic away from the library supervisor and librarian's desks and towards the main service desk.

\section{Steps to a New Space}

This space study was conducted from August 1, 2017 to June 30, 2018. However, planning for the study began in the spring 2017 semester with a meeting between the Director of Academic and Research Services and Physics Library's librarian to discuss changing the space of the Physics Library using small-scale, low-cost methods. A full-scale makeover and renovation of the space was not possible due to limited financial resources. Three goals were identified from this meeting:

(1) Create wider aisles for easier movement

(2) Create a more inviting atmosphere

(3) Adjust service desk traffic flows to ensure patrons approach the service desk when needing assistance

Rearranging furniture configurations and increasing the service desk size to enhance its presence posed the simplest and most economical route. The original layout (Figure 1) was reviewed and compared to five proposed layouts created by the Physics Library librarian. The layout seen in Figure 2 was ultimately selected due to its consolidation of highly used equipment, the opening of floor space, and relocation of the service desk to a more prominent location based on high traffic areas. This layout also included a proposed increase in service desk size, to be accomplished by repurposing the librarian's existing desk. 
Physics Library Space Layout Pre-Fall 2016

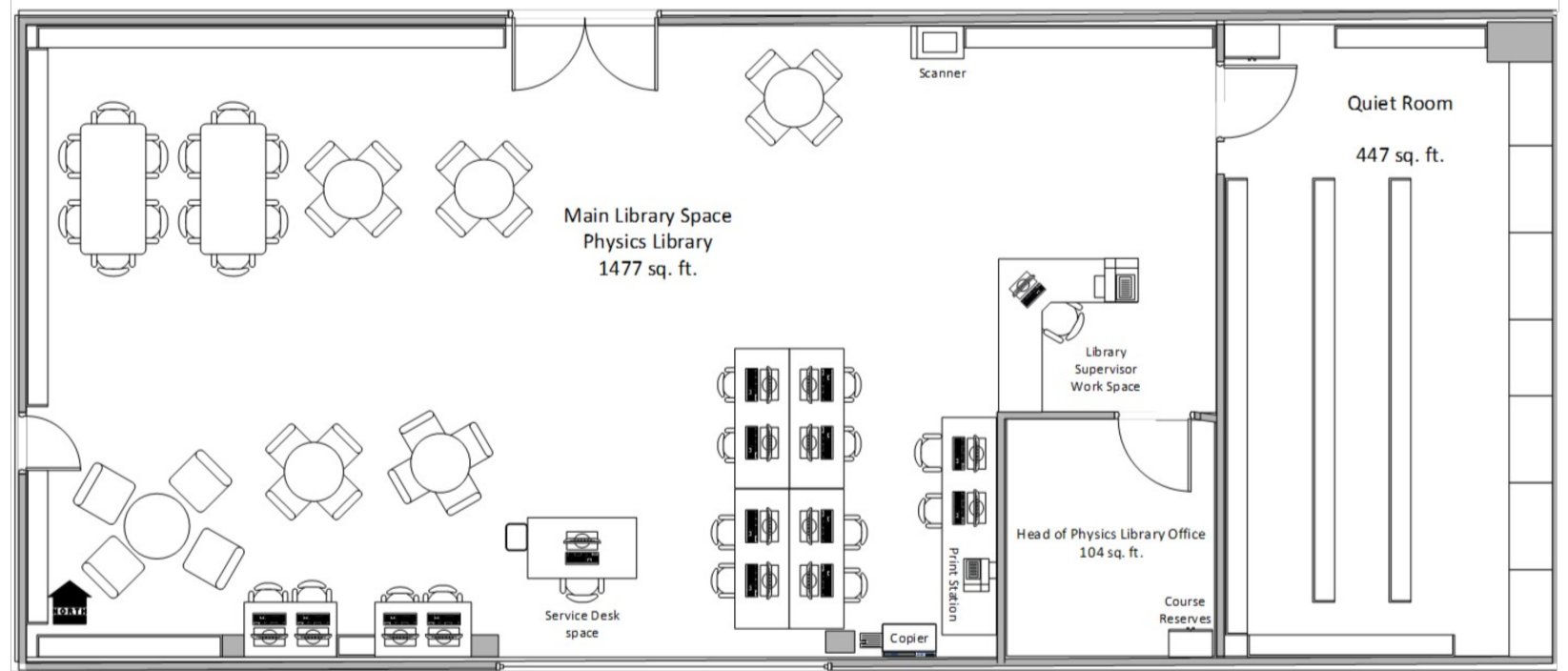

Figure 1. The Physics Library's physical layout prior to the transfer of course reserves in fall 2016 and the space's full rearrangement in July 2017.

Physics Library Space Layout Since July 2017

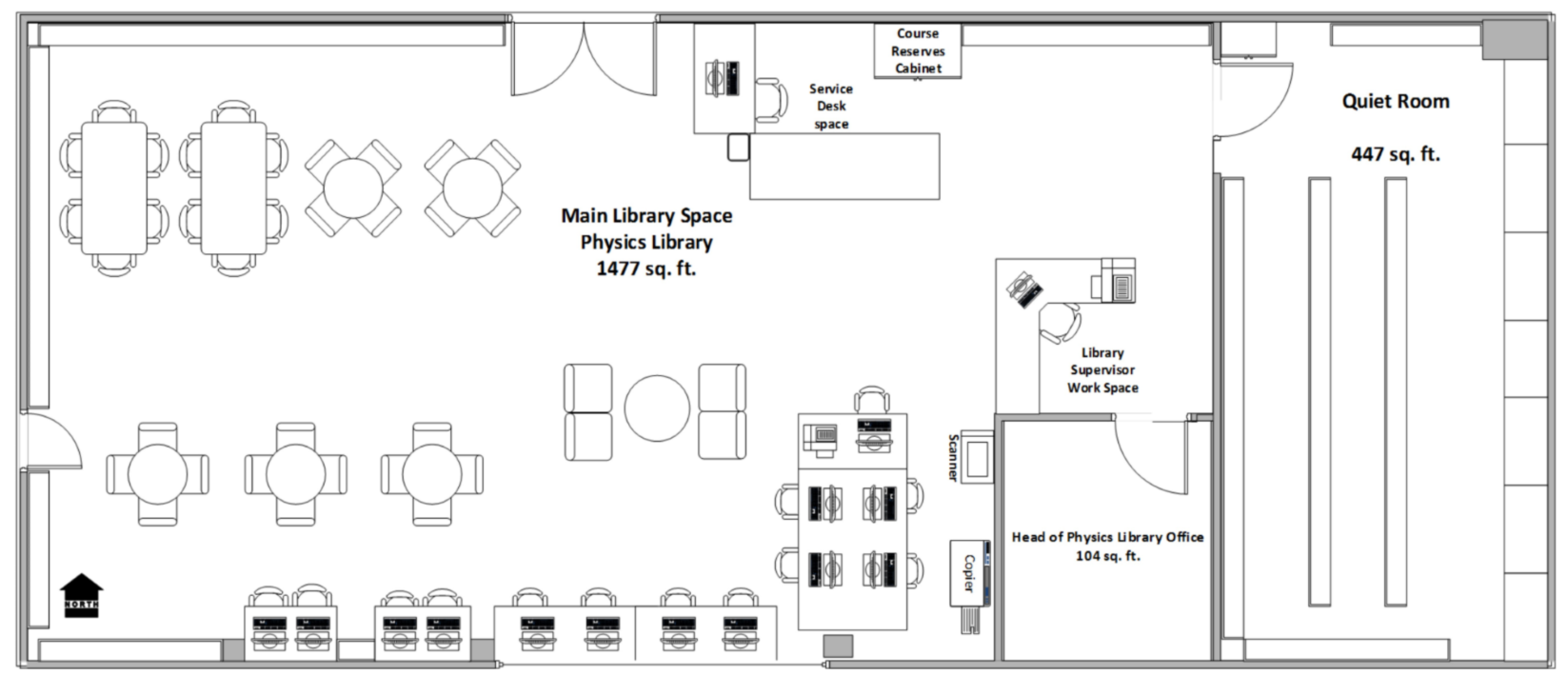

Figure 2. The Physics Library's layout post-rearrangement.

After determining the preferred layout, the Physics Library librarian worked with

University Libraries information technology (IT) staff to assess if any new wiring and ports

would be required by the proposed space arrangement. Mapping existing electrical outlets and internet ports to the proposed layout showed that it could be done without any new technology 
infrastructure being required. If new technology infrastructure had been needed a new layout would have been designed which incorporated the space's existing technology infrastructure.

With the approval of division leadership and library IT, an executive summary of the proposed plan was written explaining the purpose for the change and how the purchasing of a new desk (\$750) for the Physics Library's librarian would be the only costs accrued. The IT infrastructure in place would suffice and all other changes would come from moving or removing existing furniture and equipment. The executive summary accompanied the department's yearly equipment request at the end of May 2017 and was approved. The Physics Library was reconfigured into the new layout over the course of one day in July 2017. Of the three spaces that make up the Physics Library (quiet study room, librarian's office, and main room) only the main room was affected by the reconfiguration. The reconfiguration required one table to be removed, and a scantron reader, which the library housed for the Physics Department, to be relocated to faculty offices. Overall the space reconfiguration was completed with minimal resource investment.

\section{Reconfiguring the Space}

Prior to the rearrangement points of congestion were observed due to the placement of furniture and equipment as well as how patrons moved through the space. Group seating options were placed haphazardly across the main area while equipment was situated sporadically along the peripheries. Computer terminals jutted out into the middle of the space across from group seating thus creating narrow aisles along the path to highly used equipment. This often produced bottleneck traffic as patrons attempted to reach scanning and printing stations. Additionally, this row of computers created a physical barrier between high use points and the service desk while the library supervisor's and librarian's work spaces were located on the same side as these 
destinations. This physical arrangement of space was producing negative "costs," whether physical or psychological, to patrons and causing them to avoid the service desk in favor the library supervisor's or librarian's desks.

To decrease the "costs" of the service desk and thus increase its "benefits," the service desk was relocated from the center of the space to adjacent the library's single entry/exit point. This location applied the right turn principle, an observed economy of movement behavior, which asserts pedestrians often perceive right-side choices to require the least amount of effort (Bitgood, 1995; Bitgood, 2006). The right-turn principle played a key role in the researchers' attempt to modify assistance-seeking behaviors, especially circulation assistance, because now all patrons encounter the service desk on their right side when exiting as a way to limit their cost of effort. The new location also refocused patron attention to the service desk rather than the most immediate staff desk near them at the time of need. Other methods to increase usage of the ignored service desk and lower perceived "costs" included consolidating the service desk and all main patron destinations - computer terminals, printers, copiers, scanners, and course reserve materials - into a single zone within the library. Post rearrangement, all equipment and course reserve materials were located in immediate proximity to the service desk thus placing the desk in the time and space when patrons would most likely need it.

The relocation was coupled with an increase of service desk size by combing the original 50 " x 27 " rectangle service desk with the librarian's old 72" x 36 " desk to create a large Lshaped desk. It had been hypothesized by staff prior to the rearrangement that the previous service desk set-up blended into the background due to its size and similar appearance to computer terminals around it. By increasing the prominence and changing the location, the service desk now visually commands patrons to acknowledge its existence. Also, before the 
rearrangement there were several places where patrons could find items such as scrap paper, pencils, and ancillary tools (staplers, hole punch, etc.) which compounded the hazy messaging issues of the service desk. The increased size of the main service desk allowed for the removal of unnecessary furniture by relocating all of these items to the service desk. As a result, the purpose of the service desk was recommunicated to emphasize it as the first stop for all assistance in the library.

Another outcome of the rearrangement that improved library staff-patron interactions, is that the service desk is no longer being blocked from view by furniture and equipment. This allows library staff to easily view activities in the main room and offer help where needed. It also allows patrons to see the service desk more easily and all patrons must pass by it on their way to the most highly used spaces and equipment.

\section{Assessing Impact}

\section{Methodology}

The primary quantitative measurement used to determine the success of the library rearrangement was circulation statistics, which were used to quantify the number of check-outs by terminal. Circulation statistics were pulled from Innovative's Sierra integrated library system (ILS). The number of check-outs - regularly circulating items as well as course reserves - were reviewed before and after the move. Standard checkout numbers do not include in house usage which are counted separately in Sierra. Sierra statistics can be broken down by terminal number. Circulation statistics were pulled for the two terminals in the Physics Library - terminal one represents the service desk and terminal two records the combined totals for items checked out by both the library supervisor and librarian at their desks. Circulation numbers for items checked 
out at the main service desk were compared those to items checked out by the librarian and the library supervisor.

In person patron interactions were also tallied and analyzed. These statistics are selfreported by all library staff and recorded using tracking software. Compendium Desk Tracker software was used from the start of the study until July 2017 when the University Libraries migrated interaction tracking to Springshare's LibInsight. Patron interactions were classified as either "Directional," "Research/Reference," or "Consultation" throughout the course of the study. "Directional" refers to assistance provided by staff that does not include locating and/or demonstrating a resource (e.g., "Where is the bathroom?"). Any assistance that relates to a resource is considered "Reference/Research." "Consultation" is used to record in-depth research interactions and are primarily handled by the librarian. "Consultation" statistics were not considered in this study as all consultations should be referred to the librarian regardless of the desk the patron approaches first.

The number of patron interactions at the service desk were compared to the number of inperson interactions entered by the librarian and library supervisor. Unfortunately for this study, patron interactions were combined for the library supervisor and service desk staff until April of 2017. After that date, the patron interactions are recorded for the service desk separately; i.e. there is data for the service desk as well as for the librarian and supervisor starting in May 2017. It is worth noting that even though there is only hard data for patron interactions that are exclusive to the service desk for three months before the move, May includes the end of the semester and therefore represents heavy traffic in the Physics Library (Figure 3). 


\section{Physics Library Visitors by Date}
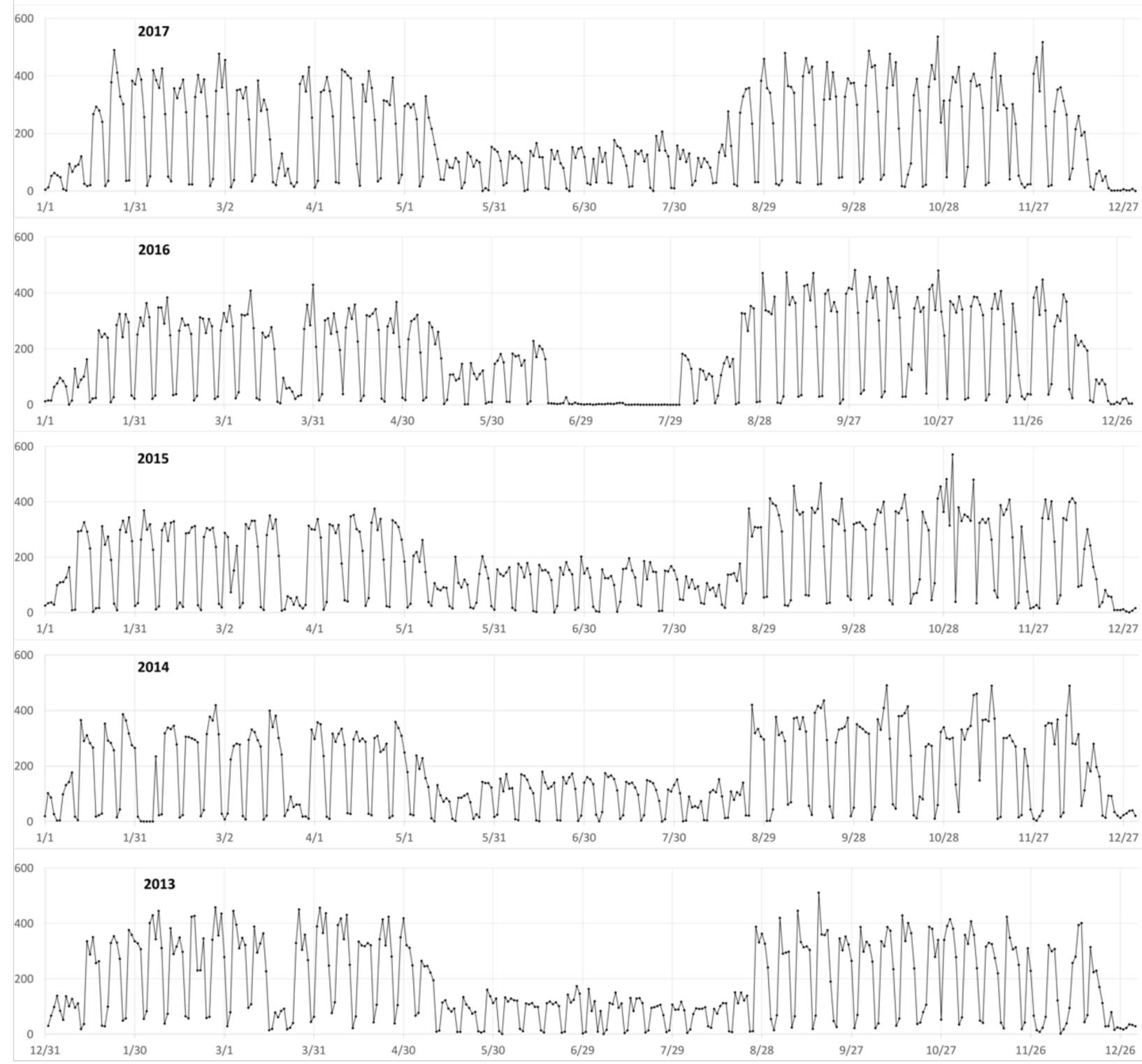

Figure 3. Five-Year Door-Count Data. Y-axis shows number of visitors while X-axis represents the date. (Note the missing data in the summer of 2016 - the door counter was not functioning in part of June through the end of July.).

Finally, the number of visitors to the Physics Library before and after the rearrangement was also examined. A uni-directional, horizontal type door counter is installed at the entrance of the Physics library. With this type of door counter, each time someone crosses the beam that extends horizontally across the door, an event is recorded. Because the counter is uni-directional it takes two events to make a single count. This assumes that each person will enter and then 
leave at a later time. Counts are sent wirelessly to a database managed by SenSource Vea software. The raw counts, each associated with a date and time, were downloaded and analyzed separately from Vea.

\section{Results}

The number of check-outs, regularly circulating as well as reserve materials, for each month are shown in Figure 4. The check-outs are separated into two groups - those items checked out at the main service desk (dashed line) and those checked out at the librarian and supervisor desks together (solid line). During the 2016 fall semester the main service desk was checking out less than half ( $31 \%$ of total check-outs) of materials. By the 2016 summer semester the two groups checked out roughly the same number of items. In fall 2016, the service desk exceeded the other desks in check-outs making up $63 \%$ of total check-outs. The spring 2017 semester saw the numbers for the two groups even out again. After that, all of the semesters including the date of the move (August 2017), the check-outs at the service desk make up $75-87 \%$ of total check-outs. The total number of check-outs for the Physics Library (both groups) increases in the time period shown. The spring semesters go from 371 total check-outs in 2016 to 395 in 2017 to 585 in 2018. For fall, there were 586 checkouts in 2016 and 905 in 2017. The summer semesters are anomalous in this aspect with 311 checkouts in 2016, 405 in 2017, and 343 in 2018. 


\section{Physics Library Check-Outs by Month}

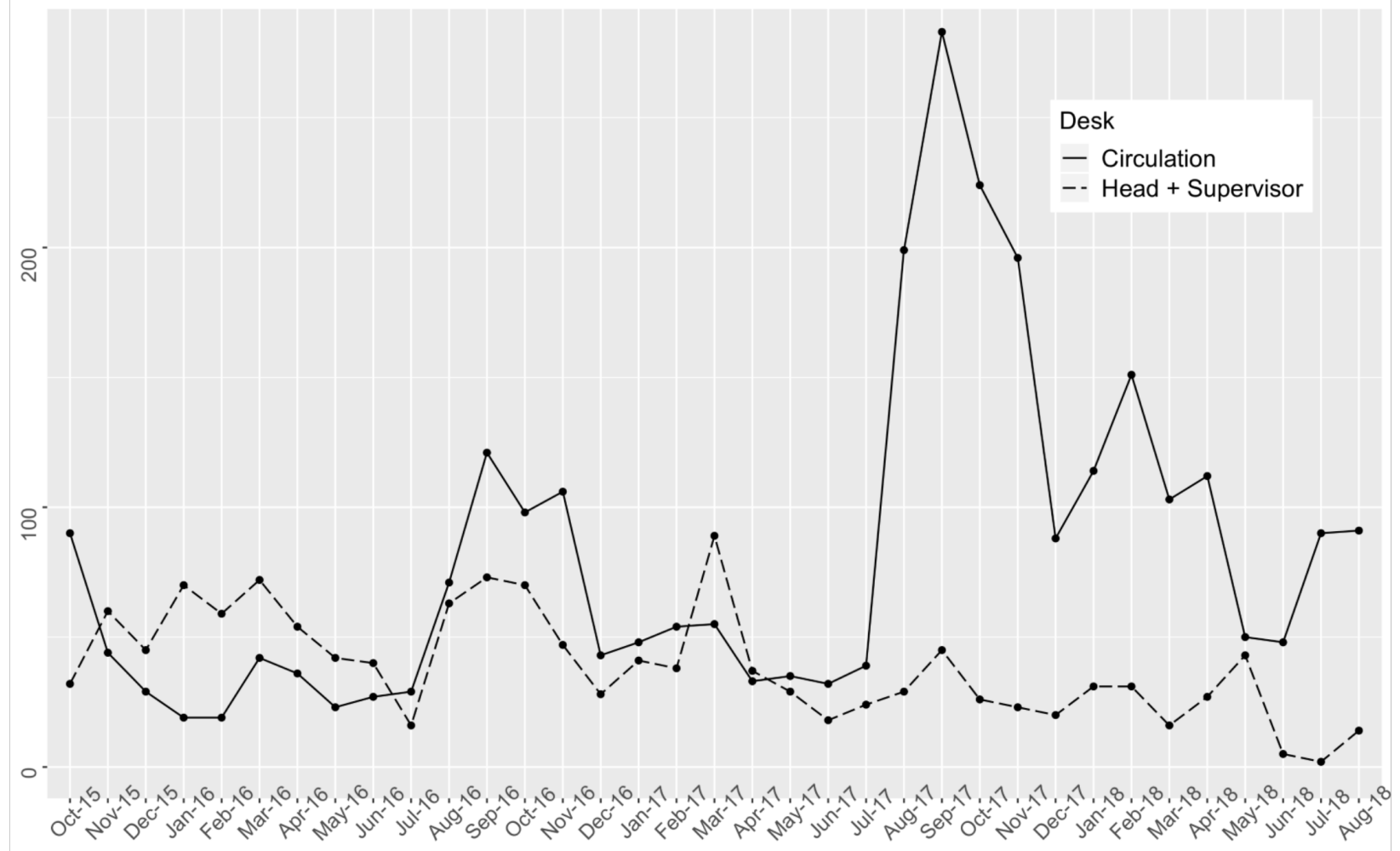

Figure 4. Check-outs for each staff terminal in Sierra (main service desk and librarian plus supervisor).

Figure 3 shows the door counts from the years preceding and the year of the study. In fiscal year (FY) 2015 (July 2014 - June 2015), there were 62,501 total visitors to the Physics Library. This increased to 64,332 visitors in FY 2016 and increased again to 65,496 in FY 2017. During the year of the study, directly before and after the rearrangement, the total number of visitors to the Physics Library dropped to 62,414 for FY 2018.

The number of patron interactions are visualized in Figure 5. Directional interactions and reference interactions data is representing in Figure 6. Each figure is separated into two groups interactions occurring at the main service desk (black bar), and interactions taking place at any other terminal/desk (grey bar). Results from the directional patron interaction data show a change from before the move to after. Before the space was redesigned (prior August 2017) the service 
desk staff recorded $12 \%-45 \%$ of total directional interactions. After the redesign, interactions at the desk increased, which service desk staff recorded $55 \%-83 \%$ of the total directional interactions. Similarly, the percentage of reference interactions recorded by staff at the main service desk increased after the reconfiguration. For both directional and reference interactions, data is anomalous for the month of February 2018. This anomalous data coincides with the library's large inventory project. The service desk was left unoccupied at times while staff completed the project. Because of this, it is not unexpected that the library supervisor and librarian would have a greater percentage of patron interactions during this period.

\section{Physics Library Directional Patron Interactions}

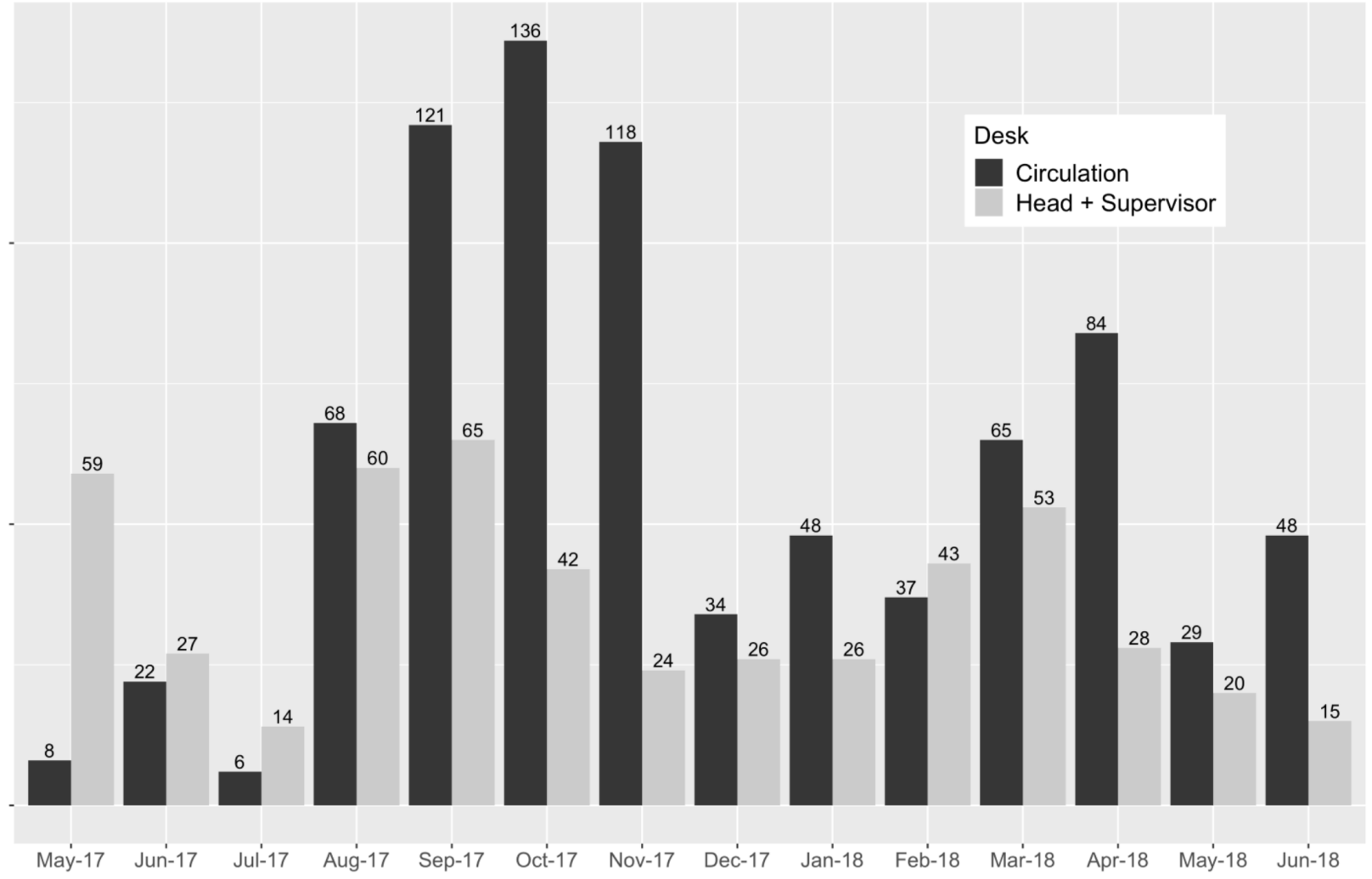

Figure 5. Directional interactions between staff and patrons. 


\section{Physics Library Research/Reference Patron Interactions}

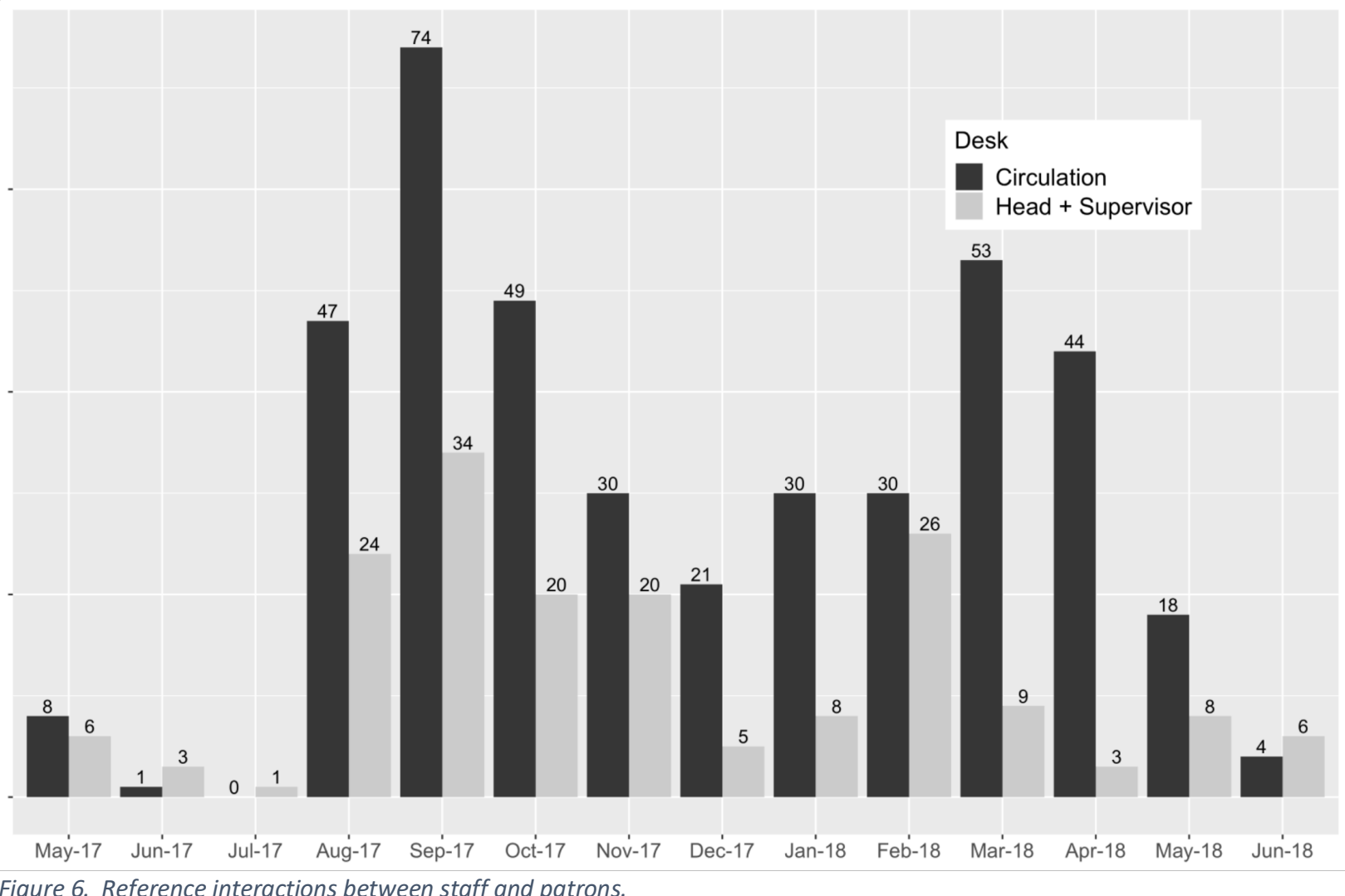

Discussion

Behavior setting theory claims that a person's environmental setting and the objects within it have direct influence on human behaviors (Scott, 2005). The behaviors patrons engage in as a result of our setting's (the library as a whole) design and use of objects (furniture, equipment, signage, etc.) impacts how library spaces, resources, and staff are used. Understanding behavior setting's role is important but recognizing the specific ways human behavior is influenced by the objects in our spaces is even more crucial. Managers who understand the intersectionality of space design and human behavior theory are better able to design library spaces which promote desired behaviors. The Physics Library rearrangement was initiated to maximize the use of limited space and address service desk issues related to patron assistance-seeking behavior in order to increase staff efficiencies. In the case of this study, addressing these issues did not 
require large amounts of financial resources or complete space remodels. Results from this study suggest that librarians apply theoretical approaches from literature with ingenuity in an attempt to innovate and find low-cost solutions to space issues when faced with poorly designed spaces and limited budgets.

Reference statistics during the study showed $65 \%-35 \%$ spilt, with the service desk handling the majority of reference and directional transactions post rearrangement. This data provides limited insight to the rearrangement's impact as it could not be compared between the service desk and the library supervisor and librarian prior to April 2017 due to the service desk and library supervisor using a single login to track reference transaction statistics. It should be noted that signage was not in the library pre- or post-rearrangement due to the size of the space so communication of services and resources were visually implied by design and arrangement.

By applying economy of movement principles to the Physics Library's environment postrearrangement, it is evident that proximity and convenience of location in relation to time of need is the most influential factor in determining a patron's decision of which service desk to seek assistance from. This influence could be seen prior to the rearrangement when the service desk was located the furthest away from the majority of patrons at their time of need. The space's rearrangement was based on understanding both Larason and Robinson's (1984) approachability model and economy of movement's impact on pedestrian behavior in order to influence patrons' subconscious "costs" calculations when selecting which service desks to approach for assistance. By strategically relocating all highly used materials and equipment into a consolidated space and placing the service desk within this zone, along with ancillary tools, the Physics Library successfully recommunicated the service desk's purpose to patrons which translated into new patron behavior patterns. 
Another component of the rearrangement, which had a small impact on service desk usage, was group seating being consolidated to the west side of the library. This opened up the space to allow easier movement through larger aisle ways and limiting the number of chairs blocking pathways. A small number of computers still continued to protrude into the center of the library but this protrusion was cut to half after the rearrangement. Additionally, the printing station was moved from a closed off corner to the end of the protruding row of computers. Patrons no longer queue in aisles due to this change which has eliminated traffic congestion and the related issues of blocked access to the service desk, equipment, and additional computers. Patrons waiting for printing now utilize soft seating located in the middle of the library adjacent to the print release station.

By maximizing the space to create a more open environment, it was expected the trend of increased visitor traffic of the Physics Library would continue as it had the previous years which would theoretically result in more use of the service desk. Surprisingly however, there was a decrease from 65,496 in FY 2017 to 62,414 in FY 2018 in the number of visitors when the study took place in. In the preceding fiscal years visitor numbers had increased by $4.5 \%$ in FY 2015 to 2.9\% in FY 2016 and 1.8\% in FY 2017. While the reason is uncertain, the decrease in visitor numbers during the study actually strengthens this study's findings and claim that patron behavior and service desk usage is directly correlated to the physical arrangement of a library's space.

\section{On Going Impact}

The rearrangement and increased service desk use has additionally led to a need for increased staff training. While the Physics Library has operated on a "referral" reference service model for 
years, it was imperative for student workers and part-time staff to participate in enhanced reference and circulation training to prepare them for increased patron engagement. Training modules were created using Blackboard course management system. New and returning service desk staff are now trained consistently, and the module provides assessment data to indicate where follow up training is needed. This change led to patrons receiving higher quality, consistent service when interacting with desk staff. Oud and Genzinger (2016) experienced similar results in regards to consistency of staff answers after utilizing a blended service desk.

Due to increased training and the service desk staff handling most of the circulation and reference transactions, the librarian and library supervisor are now free to handle more complex transactions that better utilize their expertise and manage library operations more efficiently. As seen with previous research on the single-service desk service model, having paraprofessionals conduct the majority of public service transaction has allowed the library supervisor and librarian to engage in other duties, particularly relationship building with faculty and review of collections and services (Arndt, 2010; Ryan, 2008). This is especially important for the Physics Library librarian, which is a tenure-track position, as this shift of work has allowed them to devote time to achieving the expected performance duties, service, and scholarship requirements for tenure.

\section{How to Successfully Reconfigure Your Small Academic Branch Library}

As is the case for all libraries, small academic branch libraries seek to provide spaces, resources, and services that best fulfill their communities' needs and expectations. However, when these types of libraries discover potential space design problems, methods of addressing these issues are often limited compared to their larger, free-standing counterparts. Departmental based branch libraries are especially limited by their inability to change their architectural footprint due to the lack of additional space availability, and may find that the department is unlikely to release any 
extra space for a larger library when it can be used for additional faculty office space, classrooms, or labs (Little, 2013). Finances also play a large roll in space designs, whether full remodels occur or not, and this element is wholly dependent on budgetary funds being available.

To work around these limitations, it is important for library managers to review statistical data for the service points being impacted. Goals for what the space should represent and which patron behaviors should be encouraged need to be defined (Sandy, Krishnamurthy, \& Scalfani, 2014). Once goals are established, spaces should be assessed with a critical eye towards how their arrangements are influencing patron behaviors, either wanted or unwanted. Understand how your patrons move within the library and use its resources, services, and staff, and look for ways to lower patron "costs" while increasing "benefits."

While this study proved that proximity, awareness, and packaging play a role in predicting patron behavior, as set forth in the approachability model, it also shows that physical costs to patrons potentially play the most influential role in which service point they seek assistance from. As such, it's important these are factored into your space planning goals and physical arrangements.

When initiating a space rearrangement, engage administrators at the brainstorming and planning stages to gather support and gauge the waters for potential financial resources available. Work with your information technology (IT) department to ensure all equipment requiring IT infrastructure are mapped for connectivity and power based on the proposed rearrangement configuration. Set a timeline for implementation of the new rearrangement as well as an assessment timeframe accompanied by a defined set of metrics.

Large monetary investments are not needed to engage in an effective space redesign. Purchasing one or two new pieces of furniture/equipment coupled with rearranging existing 
furniture and equipment can easily influence new patron behaviors. This low-cost method is adaptable and allows managers to experiment with different arrangements to achieve their goals.

\section{Conclusion}

Patrons decide to use a particular service desk or service point for many different reasons but it is imperative that library managers recognize their role in influencing these behaviors. If patrons aren't utilizing a particular service desk, managers should not assume that it is because their needs are being met via another avenue. Instead, managers should study their spaces to determine if this is a cause for the lack of usage and adjust their spaces, if needed, to encourage new patron behaviors. This can be achieved by understanding how patrons use and move through library spaces; rearranging the library's space so popular resources and destinations are positioned in proximity to the service desk that patrons are being encouraged towards; and designing the physical desk to recommunicate its purpose. 
REMOVING THE INVISIBILITY CLOAK / 29

\section{References}

Aabo, S., \& Audunson, R. (2012). Use of library space and the library as place. Library \& Information Science Research, 34(2), 138-149. doi:10.1016/j.lisr.2011.06.002

Arndt, T. S. (2010). Reference service without the desk. Reference Services Review, 38(1), 7180. doi:10.1108/00907321011020734

Baker, N., Furlong, K., Consiglio, D., Lankewicz Holbert, G., Milberg, C., Reynolds, K., \& Wilson, J. (2018). Demonstrating the value of "library as place" with the MISO survey. Performance Measurement and Metrics, 19(2), 111-120. doi:10.1108/PMM-01-2018-0004

"Barker, Roger Garlock." (2002). In A. J. Chapman, W. A. Conroy \& N. Sheehy (Eds.), Biographical dictionary of psychology (2nd ed.,). London, UK: Routledge. Retrieved from http://0search.credoreference.com.library.uark.edu/content/entry/routbiopsy/barker_roger_garlock/ $\underline{0}$

Bartle, L. R. (1999). Designing an active academic reference service point. Reference \& User Services Quarterly, 38(4), 395-401.

Becket, M., \& Smith, H. B. (1986). Designing a reference station for the information age. Library Journal, 111(7), 42-46.

Bitgood, S., \& Dukes, S. (2006). Not another step! Economy of movement and pedestrian choice point behavior in shopping malls. Environment and Behavior, 38(3), 394-405. doi: $10.1177 / 0013916505280081$ 
REMOVING THE INVISIBILITY CLOAK / 30

Bitgood, S. (2006). An analysis of visitor circulation: Movement patterns and the general value principle. Curator: The Museum Journal, 49(4), 463-475. doi:10.1111/j.21516952.2006.tb00237.x

Bitgood, S.C. (1995). Visitor circulation: Is there really a right-turn bias? Visitor Behavior, 10(1), 5. Retrieved from http://kora.matrix.msu.edu/files/31/173/1F-AD-85-8-VSA-a0a1q6a_5730.pdf

Bonnet, J. L., \& McAlexander, B. (2012). Structural diversity in academic libraries: A study of librarian approachability. The Journal of Academic Librarianship, 38(5), 277-286. doi:10.1016/j.acalib.2012.06.002

Bonnet, J. L., \& McAlexander, B. (2013). First impressions and the reference encounter: The influence of affect and clothing on librarian approachability. The Journal of Academic Librarianship, 39(4), 335-346. doi:10.1016/j.acalib.2012.11.025

Campbell, J. D. (2007). Still shaking the conceptual foundations of reference: A perspective. The Reference Librarian, 48(2), 21-24. doi:10.1300/J120v48n02_05

Cha, S. H., \& Kim, T. W. (2015). What matters for students' use of physical library space? The Journal of Academic Librarianship, 41(3), 274-279. doi:10.1016/j.acalib.2015.03.014

Cortes-Villalba, C., Gil-Leiva, I., \& Artacho-Ramirez, M. A. (2017). Emotional design application to evaluate user impressions of library information desks. Library \& Information Science Research, 39(4), 311-318. doi:10.1016/j.lisr.2017.11.004

Crooks, J. M. (1983). Designing the perfect reference desk. Library Journal, 108(10), 970-972. 
Dinkins, D., \& Ryan, S. M. (2010). Measuring referrals: The use of paraprofessionals at the reference desk. The Journal of Academic Librarianship, 36(4), 279-286. doi:10.1016/j.acalib.2010.05.001

Ford, B. J. (1986). Reference beyond (and without) the reference desk. College and Research Libraries, 47(5), 491.

Heikkila-Furrey, J., Kearns, S. K., \& Littrell, L. (2007). Reference by your side: Redesigning the library help desk. The Reference Librarian, 48(2), 41-59. doi:10.1300/J120v48n02_08

Houston, A. M. (2015). Revisiting library as place: Balancing space planning priorities by focusing on core purpose. Reference and User Services Quarterly, 55(2), 84-86.

Humphries, A. W. (1993). Designing a functional reference desk - planning to completion. $R Q$, 33(1), 35-40.

Jazwinski, C. H., \& Walcheski, C. H. (2011). At the mall with children: Group size and pedestrian economy of movement. Environment and Behavior, 43(3), 363-386. doi:10.1177/0013916510364461

Kim, J. (2016). Dimensions of user perception of academic library as place. The Journal of Academic Librarianship, 42(5), 509-514. doi:10.1016/j.acalib.2016.06.013

Larason, L., \& Robinson, J. S. (1984). The reference desk: Service point or barrier? RQ, 23(3), 332-338. 
Lewis, D. W. (1995). Traditional reference is dead, now let's move on to important questions. The Journal of Academic Librarianship, 21(1), 10-12. doi:10.1016/0099-1333(95)90146-9

Little, G. (2013). The space race. The Journal of Academic Librarianship, 39(4), 351-353. doi:10.1016/j.acalib.2013.05.001

Macdonald, H. (1986). Designing a reference desk. Texas Library Journal, 62, 175-179.

Mandel, L. (2016). Visualizing the library as place. Performance Measurement and Metrics, 17(2), 165-174. doi:10.1108/PMM-04-2016-0016

Maxymuk, J. (2010). Library as a place in space. The Bottom Line, 23(3), 128-131. doi:10.1108/08880451011087702

McCormick, E. J. (1970). Human factors engineering (Third ed.). New York: McGraw-Hill.

Miles, D. B. (2013). Shall we get rid of the reference desk? Reference \& User Services Quarterly, 52(4), 320-333. doi:10.5860/rusq.52n4.320

Moore, R. L. (1953). Pedestrian choice and judgment. OR, 4(1), 3-10. doi:10.2307/3006905

Morgan, L. (1980). Patron preference in reference service points. $R Q$, 19(4), 373-375.

O'Kelly, M., Scott-Webber, L., Garrison, J., \& Meyer, K. (2017). Can a library building's design cue new behaviors?: A case study. Portal: Libraries and the Academy, 17(4), 843-862. doi:10.1353/pla.2017.0049 
O'Neill, K.L., \& Guilfoyle, B.A. (2015). Sign, sign, everywhere a sign: What does "reference" mean to academic library users? The Journal of Academic Librarianship 41(4), 386-393. doi: 10.1016/j.acalib.2015.05.007

Oud, J., \& Genzinger, P. (2016). Aiming for service excellence: Implementing a plan for customer service quality at a blended service desk. Journal of Access Services, 13(2), 112130. doi: $10.1080 / 15367967.2016 .1161521$

Pierson, R. (1977). On reference desks. $R Q, 17(2), 137-138$.

Pierson, R. (1985). Appropriate settings for reference service. Reference Services Review, 13(3), 13-29. doi://10.1108/eb048907

Ryan, S. M. (2008). Reference transactions analysis: The cost-effectiveness of staffing a traditional academic reference desk. The Journal of Academic Librarianship, 34(5), 389399. doi://doi.org/10.1016/j.acalib.2008.06.002

Sandy, J. H., Krishnamurthy, M., \& Scalfani, V. F. (2014). Repurposing space in a science and engineering library: Considerations for a successful outcome. The Journal of Academic Librarianship, 40(3-4), 388-393. doi:10.1016/j.acalib.2014.03.015

Schulte, S. J. (2011). Eliminating traditional reference services in an academic health sciences library: A case study. Journal of the Medical Library Association, 99(4), 273-279. doi:10.3163/1536-5050.99.4.004

Scott, M. M. (2005). A powerful theory and a paradox - ecological psychologists after Barker. Environment and Behavior, 37(3), 295-329. doi:10.1177/0013916504270696 
Sider, L. G. (2016). Improving the patron experience: Sterling memorial library's single service point. Journal of Access Services, 13(2), 91-100. doi:10.1080/15367967.2016.1161519

van Beynen, K., Pettijohn, P., \& Carrel, M. (2010). Using pedestrian choice research to facilitate resource engagement in a midsized academic library. The Journal of Academic Librarianship, 36(5), 412-419. doi:10.1016/j.acalib.2010.06.005

Venner, M. A., \& Keshmiripour, S. (2016). X marks the spot: Creating and managing a single service point to improve customer service and maximize resources. Journal of Access Services, 13(2), 101-111. doi:10.1080/15367967.2016.1161520

Warnement, M. (2003). Size matters: The debate over reference desk height. Portal: Libraries and the Academy, 3(1), 79-87. doi:10.1353/pla.2003.0021

Waxman, L., Clemons, S., Banning, J., \& McKelfresh, D. (2007). The library as place. New Library World, 108(9/10), 424-434. doi:10.1108/03074800710823953 